\title{
PENTINGNYA DIAGNOSA KEPERAWATAN DALAM MENENTUKAN INTERVENSI KEPERAWATAN
}

\author{
Inayah Husna Sibarani / inayahhusna08@gmail.com
}

\section{LATAR BELAKANG}

Rencana asuhan diagnosis keperawatan disusun sesuai abjad supaya pernyataan diagnosis mudah ditemukan. Diagnosis disusun per kata dengan tujuan menekankan konsep kunci dari kata pertama dalam pernyataan diagnosis. Sebagai contoh, Penyangkalan tidak efektif lebih mudah ditemukan di dalam indeks bila ditulis sebagai Penyangkalan, tidak efektif.

Diagnosis keperawatan merupakan sebuah label singkat yang menggambarkan kondisi pasien yang diobservasi dalam praktik. Kondisi ini dapat berupa masalah - masalah aktual atau potensial atau diagnosis sejahtera. Menggunakan terminologi NANDA International, potensi masalah dinyatakan sebagai Risiko. Lampiran memuat daftar deskriptor aksis (yang sebelumnya disebut "kualifer") yang digunakan dalam banyak pernyataan diagnosis (misalnya, akut, perubahan, gangguan). Penambahan kata keterangan mungkin diperlukan agar diagnosis menjadi lebih tepat dan jelas.

Pentingnya seorang perawat untuk menentukan diagnosa keperawatan karena dengan menentukan diagnosa keperawatan perawat bisa memutuskan tindakan apa yang akan dilakukan dan asuhan keperawatan yang bagaimana yang akan diberikan kepada klien. Dengan begitu perawat tidak akan membuat klien merasa tidak aman dan nyaman dengan asuhan keperawatan yang diberikan perawat. Dari diagnosa ini juga bisa menentukan intervensi keperawatan yang nantinya menghasilkan implementasi proses keperawatan.

Untuk dapat merumuskan diagnosa keperawatan dibutuhkan kemampuan analisis yang tinggi sehingga diperlukan sumber daya manusia yang capable dan mempunyai motivasi kuat untuk maju serta berpandangan maju (futuristic). Pada status pasien yang telah dikaji terlihat bahwa perawat hanya memilih saja diagnosa keperawatan yang telah disediakan di bagian samping format pengkajian. Hal ini lebih memudahkan perawat akan tetapi dapat menyebabkan perawat menjadi kurang inisiatif untuk menganalisa data kemudian merumuskan diagnosa keperawatan sendiri apabila ditemukan data yang berbeda. Kondisi ini menimbulkan kualitas pendokumentasian diagnosa keperawatan. 


\section{METODE}

Metode yang digunakan dalam kajian ini menggunakan metode kualitatif. Metode ini bersifat memberikan penjelasan dengan membuat analisis. Proses pengkajian ini lebih menggunakan landasan teori dengan mengumpulkan data, bereksplorasi bebas yang telah disimpulkan dari berbagai sumber-sumber, yaitu buku, majalah, koran, jurnal print maupun jurnal online bertema perencanaan keperawatan. Saya membaca dari berbagai referensi berupa buku, jurnal print maupun jurnal online. Melalui metode ini saya dapat memahami dan mengidentikasi diagnosa keperawatan dan bagaimana dalam menentukannya. Artikel yang digunakan minimal menggunakan 10 referensi yang diterbitkan tidak dibawah tahun 2012 untuk tahun terakhirnya.

\section{HASIL}

Berdasarkan hasil pencarian literature review yang saya dapatkan bahwa banyak perawat di rumah sakit yang masih kurang paham dengan menentukan diagnosa keperawatan yang benar.

Peran perawat sebagai pemberi pelayanan terkadang tidak sesuai dengan standar dan kurang optimal. Pada prakteknya, perawat sering mengalami kesulitan dalam melaksanakan asuhan keperawatan. Sering sekali perawat kesulitan dalam hal menetapkan diagnosa keperawatan yang tepat bagi pasien. Pada kasus yang lain, data dikumpulkan tanpa menyadari mengenai apa diagnosanya?. Perawat juga mengumpulkan data yang mempunyai relevansi yang rendah dengan diagnosa keperawatan tertentu. Penelitian menunjukkan bahwa rendahnya keakuratan dalam diagnosa keperawatan berkaitan dengan banyaknya jumlah data yang relevansinya rendah (Nurjannah I, 2012).

Secara umum, dalam pernyataan diagnosa keperawatan dapat dibedakan atas dua bagian yaitu bagian respons klien dan kondisi yang mempengaruhinya. Atau dalam istilah Carpenito (1995), adanya pernyataan P untuk Problem dan E untuk Etiologi. Dalam format NANDA, dapat dinyatakan bahwa respons dapat dianggap serupa dengan label diagnostik dan kondisi serupa dengan etiologi atau faktor yang berhubungan.

Diagnosis keperawatan merupakan sebuah label singkat yang menggambarkan kondisi pasien yang diobservasi dalam praktik. Kondisi ini dapat berupa masalah - masalah aktual atau potensial atau diagnosis sejahtera. Menggunakan terminologi NANDA International, potensi 
masalah dinyatakan sebagai Risiko. Lampiran C memuat daftar deskriptor aksis (yang sebelumnya disebut "kualifer") yang digunakan dalam banyak pernyataan diagnosis (misanya, akut, perubahan, gangguan). Penambahan kata keterangan mungkin diperlukan agar diagnosis menjadi lebih tepat dan jelas.

Definisi untuk masing - masing diagnosis keperawatan, membantu perawat dalam melakukan verifikasi diagnosis keperawatan tertentu. Kecuali dengan kata lain disebutkan, defnisi dalam buku ini diambil dari taksonomi NANDA International.

\section{PEMBAHASAN}

Masing-masing rencana asuhan meliputi pernyataan diagnosis keperawatan, faktor yang berhubungan atau faktor risiko, saran penggunaan, dan aktivitas keperawatan.

Proses keperawatan adalah aktivitas yang mempunyai maksud yaitu praktik keperawatan yang dilakukan dengan cara yang sistematik. Selama melaksanakan proses keperawatan, perawat menggunakan dasar pengetahuan yang komprehensif untuk mengkaji status kesehatan klien, membuat penilaian yang bijaksana dan mendiagnosa, mengidentifikasi hasil akhir kesehatan klien dan merencanakan, menerapkan dan mengevaluasi tindakan keperawatan yang tepat guna mencapai hasil akhir tersebut (Dermawan, 2012).

Proses menjalankan tugas sebagai pemberi asuhan keperawatan, perawat berwenang untuk menegakkan diagnosis keperawatan (Pasal 30 UU No.38 tahun 2014). Kegiatan analisis data dalam perumusan diagnosa keperawatan merupakan kemampuan kognitif dalam pengembangan daya berfikir dan penalaran yang dipengaruhi oleh latar belakang ilmu dan pengetahuan yang dimiliki seorang perawat. Analisis data dalam perumusan diagnosa keperawatan dimulai dengan pengelompokan data yang diperoleh dari anamnesa, pengamatan dan pemeriksaan fisik lalu hasil yang didapat dibandingkan dengan standar (kondisi normal), sehingga dapat diketahui permasalahan kesehatan yang dialami pasien dan dapat dirumuskan masalah kesehatan. Saat melakukan analisis data untuk perumusan diagnosa keperawatan kemampuan seorang perawat sangat diperlukan untuk mengkaitkan data dan menghubungkan data tersebut dengan konsep teori, sehingga perawat mampu merumuskan diagnosa keperawatan dengan tepat (Dermawan, 2012).

Diagnosa keperawatan merupakan keputusan klinik tentang respon individu, keluarga dan masyarakat tentang masalah kesehatan aktual atau potensial, dimana berdasarkan pendidikan dan pengalamannya, perawat secara akuntabilitas dapat mengidentifikasi dan 
memberikan intervensi secara pasti untuk menjaga, menurunkan, membatasi, mencegah dan merubah status kesehatan klien (Yeni, 2008).

Defenisi diagnosa keperawatan menurut NANDA ialah dari istilah penegakan diagnosis menunjukkan proses penalaran, sedangkan istilah diagnosis adalah pernyataan atau kesimpulan fenomena. Nama diagnosis yang baku menurut NANDA disebut judul diagnosis, dan pernyataan masalah klien, yang terdiri dari judul diagnosis plus etiologi (hubungan kausal antara masalah dan faktor yang berhubungan atau faktor risiko) itulah yang disebut dengan diagnosis keperawatan. (Kozier, dkk, 2010).

Diagnosa keperawatan juga diartikan sebagai suatu kesimpulan yang dihasilkan dari analisa data, diagnosa keperawatan adalah penilaian klinik mengenai respon individu keluarga, atau komunitas terhadap masalah kesehatan atau proses kehidupan yang aktual atau potensial, diagnosa keperawatan memberikan dasar untuk pemilihan intervensi keperawatan untuk mencapai hasil yang merupakan tanggung jawab perawat. (Carpenito, 2009).

Menurut Nursing Interventions Classification (NIC) (2013), intervensi keperawatan merupakan suatu perawatan yang dilakukan perawat berdasarkan penilaian klinis dan pengetahuan perawat untuk meningkatkan outcoem pasien/klien.

Intervensi keperawatan adalah panduan untuk perilaku spesifik yang diharapkan dari klien, dan atau/atau tindakan yang harus dilakukan oleh perawat. Intervensi dilakukan untuk membantuk klien mencapai hasil yang diharapkan (Deswani, 2009).

Tiga komponen utama yang harus ada dalam sebuah rencana asuhan keperawatan sebagai berikut.

1. Diagnosis keperawatan atau masalah yang diprioritaskan.

2. Kriteria hasil, yaitu apa hasil yang diharapkan dan kapan anda ingin mengetahui hasil yang diharapkan tersebut.

3. Intervensi, yaitu apa yang harus dilakukan untuk mencapai tujuan atau kriteria hasil.

Langkah pertama dalam memberikan asuhan keperawatan untuk membantu klien mencapai kesejahteraan adalah melalui pengkajian terhadap kemampuan klien melakukan perawatan diri, pengkajian jaringan dukungan sosial klien, dan pengkajian lingkungan tempat klien tinggal dan berinteraksi. Selanjutnya intervensi yang memudahkan klien mencapai tujuan diimplementasikan oleh perawat. Intervensi ini difokuskan pada peningkatan kemampuan klien untuk melakukan perawatan diri, membantu klien mengembangkan sistem dukungan sosial, 
atau memelihara dan mengubah lingkungan untuk mempermudah upaya mencapai kesejahteraan.

Pada saat pengkajian, perawat perlu memperhatikan dan mempertimbangkan proses kesehatan apa yang sedang berlangsung pada diri klien. Karena dengan memperhatikan perilaku klien dalam menyelesaikan suatu proses akan mempermudah perumusan diagnosa keperawatan. Apabila suatu proses terjadi, klien harus dapat menyelesaikan sejumlah tahapan sebelum mencapai sasaran. Dengan mengidentifikasi perilaku dan langkah yang dilakukan oleh klien, perawat dapat menilai kemajuan dalam menyelesaikan proses dan menggunakan informasi tersebut untuk merumuskan diagnosa keperawatan.

Intervensi dan Aktivitas Keperawatan, perawat memilih intervesi keperawatan. Intervensi NIC yang terdapat dalam daftar adalah: Promosi Mekanika Tubuh, Asuhan Inkontinensia Usus, Stimulasi Kognitif, Manajemen Delirium, Manajemen Lingkungan: Keamanan, Promosi Latihan Fisik: Latihan Kekuatan, Promosi Latihan Fisik: Peregangan, Terapi Latihan: Ambulasi, Terapi Latihan: Keseimbangan, Terapi Latihan: Mobilitas Sendi, Terapi Latihan: Pengendalian Otot, Pencegahan Jatuh, Manajemen Medikasi, Manajemen Sensasi Perifer, Identifikasi Risiko, Pencegahan Kejang, Bantuan Perawatan Diri, Surveilans, Pendidikan Kesehatan: Keamanan Bayi, dan Pendidikan Kesehatan: Keamanan Balita.

Terdapat banyak kemungkinan intervensi NIC karena terdapat banyak faktor risiko untuk jatuh. Perawat menentukan bahwa hanya Manajemen Lingkungan: Keamanan, Pencegahan Jatuh, dan Identifkasi Risiko sesuai untuk tujuan yang dipilih untuk pasien.

Intervensi NIC memberi arahan untuk pemilihan aktivitas keperawatan, tetapi masih secara umum. Dalam menulis program keperawatan secara individual untuk pasien, perawat memilih hal-hal berikut ini dari daftar aktivitas keperawatan:

- Identifkasi karakteristik lingkungan yang dapat meningkatkan potensi jatuh (misalnya terpeleset dilantai dan tangga terbuka) (NIC).

- Orientasikan kembali pasien pada realitas dan lingkungan saat ini jika dibutuhkan. Atur letak barang-barang dalam jangkauan pasien (NIC).

- Sediakan alat untuk memanggil bantuan (misalnya, bel atau lampu pemanggil) pada pasien yang mengalami ketergantungan ketika pemberi asuhan tidak ada (NIC).

Seluruh program perawatan yang telah disebutkan dapat menjadi bagian dari rencana asuhan untuk pasien. Pada saat intervensi atau aktivitas tidak lagi dapat dilaksanakan, perawat menghapusnya dari rencana perawatan. Aktivitas baru harus ditambahkan sesuai dengan kebutuhan. Contoh ini menunjukkan proses yang digunakan untuk mengembangkan sebuah 
rencana perawatan untuk satu diagnosis keperawatan. Diagnosis keperawatan yang lain mungkin juga sesuai untuk pasien.

\section{PENUTUP}

Diagnosa keperawatan merupakan suatu kesimpulan yang dihasilkan dari analisa data, diagnosa keperawatan adalah penilaian klinik mengenai respon individu keluarga, atau komunitas terhadap masalah kesehatan. Salah satu proses keperawatan adalah diagnosa keperawatan, diagnose keperawatan merupakan suatu hal yang penting untuk menghasilkan dan meningkatkan suatu intervensi keperawatan. Diagnosa keperawatan ini terdiri dari komponen diagnose keperawatan, tipe-tipe diagnose keperawatan dan langkah-langkah untuk menentukan diagnosa keperawatan. Untuk menjadi seorang perawat profesional hal yang paling penting harus dapat menguasai materi dan teori konsep dasar asuhan keperawatan dengan tergolong kategori baik. Tingkat pengetahuan yang tergolong baik hal ini sejalan dengan penerapan asuhan keperawatan yang baik. 


\section{DAFTAR PUSTAKA}

Apriani, Heni. (2015). IDENTIFIKASI DIAGNOSIS KEPERAWATAN PADA PASIEN DI RUANG PARU SEBUAH RUMAH SAKIT. Jurnal Keperawatan, Volume XI, No. 1. Hal: 107-111.

Astar, Fatmawati. Tamsah, Hasmin. Kadir, Ikhasana. (2018). PENGARUH PELAYANAN ASUHAN KEPERAWATAN TERHADAP KEPUASAN PASIEN DI PUSKESMAS TAKALALA KABUPATEN SOPPENG. MIRAI : JOURNAL OF MANAGEMENT VOL. 1 NO. 2. Hal: 33-53.

Nuryani, Nurul. Susanti, Dwi Dahlia. (2014). HUBUNGAN PENGETAHUAN PERAWAT DENGAN KELENGKAPAN DOKUMENTASI ASUHAN KEPERAWATAN DI RSUD dr. SOEKARDJO KOTA TASIKMALAYA. Jurnal Manajemen Informasi Kesehatan Indonesia, Vol.3, No.1. Hal: 5-9

Pratiwi, Mahardika. Ain, Hurun. Hanan, Abdul. (2018). FRAKSI LEMAK DAN KARAKTERISTIK ELECTROCARDIOGRAPHY (ECG) PADA PASIEN SINDROM KORONER AKUT (SKA). JURNAL KEPERAWATAN TERAPAN, VOLUME 4, NO. 1. Hal: $50-58$.

Rinawati, Prema. (2018). KOMPETENSI PERAWAT DALAM MERUMUSKAN DIAGNOSA KEPERAWATAN PADA PASIEN DI RUANG RAWAT INAP RSUD TUGUREJO SEMARANG. Manuscript: repository Unimus. Hal: 1-9.

Rofi'I, Muhammad. Warsito, Edi Bambang. dkk. (2018). Diagnosa Keperawatan Yang Sering Ditegakkan Perawat Pada Pasien Tuberkulosis Paru Di Rumah Sakit. Jurnal Kepemimpinan dan Manajemen Keperawatan, Vol 1 No 2. Hal: 1-8

S, Wulandini Putri. Krianto, Tri. Priwahyuni, Yuyun. (2016). FAKTOR-FAKTOR YANG BERHUBUNGAN DENGAN PENDOKUMENTASIAN ASUHAN KEPERAWATAN DI RUMAH SAKIT JIWA. NERS JURNAL KEPERAWATAN, Volume 12, No.2. Hal.131-142.

Sari, Harum Selfia. Agianto. Wahid, Abdurrahman. (2015). BATASAN KARAKTERISTIK DAN FAKTOR YANG BERHUBUNGAN (ETIOLOGI) DIAGNOSA KEPERAWATAN: HAMBATAN MOBILITAS FISIK PADA PASIEN STROKE. Batasan Karakteristik dan Etiologi DK Vol.3/No.1. Hal: 12-19. 
Simamora, R. H., Bukit, E., Purba, J. M., \& Siahaan, J. (2017). Penguatan kinerja perawat dalam pemberian asuhan keperawatan melalui pelatihan ronde keperawatan di rumah sakit royal prima medan. Jurnal pengabdian kepada masyarakat, 23(2), 300-304.

Supratti. Ashriady. (2016). PENDOKUMENTASIAN STANDAR ASUHAN KEPERAWATAN DI RUMAH SAKIT UMUM DAERAH MAMUJU, INDONESIA. Jurnal Kesehatan MANARANG, Volume 2, Nomor 1. Hal: 44-50

Wilkinson, Judith M. 2020. Diagnosis Keperawatan. Jakarta: Penerbit Buku Kedokteran EGC. Edisi 10.

Wirdah, Husnul \& Yusuf, Muhammad. (2016). Penerapan Asuhan Keperawatan Oleh Perawat Pelaksana di Rumah Sakit Banda Aceh. Banda Aceh: Universitas Syah Kuala. 